\title{
Гидрофизические
}

\section{лазерно-интерференционные приемные системы: конструктивные особенности и области применения}

Г. И. Долгих, С. С. Будрин; С. Г. Долгих, А. А. Плотников, В. А. Чупин, В. А. Швец, С. В. Яковенко

Тихоокеанский океанологический институт им. В.И. Ильичева Дальневосточного отделения Российской академии наук, Владивосток, Россия

\begin{abstract}
Приведен обзор по лазерно-интерференционным измерителям вариаций гидросферного давления различных модификаций, предназначенных для измерения вариаций гидросферного давления в частотном диапазоне от 0 (условно) до 1000 Гц с точностью 1 мПа. Кратко обсуждены некоторые результаты применения данных лазерно-интерференционных систем при регистрации колебаний и волн инфразвукового и звукового диапазонов.
\end{abstract}

Ключевые слова: гидрофизические лазерно-интерференционные приемные системы, гидроакустические излучатели, гидроакустика, ветровые волны, сейши, инфрагравитационные волны, внутренние волны

\section{Hydrophysical Laser-Interference Receiving Systems: Features And Application}

G. G. I. Dolgikh, S. S. Budrin; S. S. Dolgikh, A. A. Plotnikov, V. A. Chupin, V. A. Shvets, S. V. Yakovenko, V.I. Il'ichev Pacific Oceanological Institute Far Eastern Branch of the Russian Academy of Sciences, Vladivostok, Russia

\begin{abstract}
Several types of laser-interference instruments for measuring variations of hydrosphere's pressure are reviewed in this article. Instruments' frequency range is from conditionally $\mathrm{O} \mathrm{Hz}$ (unbounded in principle) to $1000 \mathrm{~Hz}$ with accuracy of $1 \mathrm{mPa}$. Some of the results of using these laser-interference systems for recording vibrations and waves in the infrasound and sound ranges are briefly discussed.
\end{abstract}

Key words: hydrophysical laser-interference receiving systems, sonar emitters, hydroacostics, wind waves, seiche, infra-gravity waves, internal wave

\section{ВВЕДЕНИЕ}

Решение многих фундаментальных задач зависит в первую очередь от полученных экспериментальных результатов, качество которых определяется применяемой в исследованиях аппаратурой. Дан ${ }^{-}$ ная аппаратура должна удовлетворять следующим основным двум требованиям: 1) иметь предельную чувствительность, при которой возможны фоновые измерения изучаемых параметров; 2) обладать наивысшим частотным и динамическим диапазонами. Важность данных требований возрастает при изучении природных процессов на этапах 
их возникновения и развития. В любой области исследования очень сложно определить момент начала возникновения того или иного природного процесса. В океанологии сложность проведения данных исследований связана с тем, что возникающие природные процессы и явления имеют большие временные и пространственные масштабы. Большие временные и пространственные масштабы требуют применения при изучении данных природных процессов аппаратуры, в идеале обладающей неограниченным частотным и динамическим диапазонами при предельно достижимой чувствительности. Предельно достижимая чувствительность определяется межатомным взаимодействием. Можно полагать, что минимальная чувствительность определяется размерами атома, а максимальная - флуктуациями атома. Невозможность создания аппаратуры, удовлетворяющей вышеперечисленным требованиям, привела к бурному применению параметрических методов при проведении исследований природных процессов и явлений, особенно в инфразвуковом диапазоне. Так, в океанологии широко применяются высокочувствительные установки, рабочий диапазон частот которых не позволяет выполнять прямые измерения изучаемых параметров в инфразвуковом диапазоне. В этом случае применение параметрических методов возможно только при выполнении одного из следующих условий: 1) нелинейное взаимодействие процессов и явлений различных пространственных и временных масштабов; 2) возбуждение высокочастотных процессов и явлений низкочастотными в среде, обладающей большой нелинейностью. Поверхностный анализ выполнения данных условий позволяет понять, что при проведении исследований различных процессов на основе применения параметрических методов не может быть и речи об изучении физики процесса их возникновения, так как взаимодействие процессов и явлений различных временных и пространственных масштабов или возбуждение высокочастотных процессов и явлений низкочастотными наблюдается лишь на последних стадиях их развития. Применение различных уровнемеров, мареографов и т.п. в океанологии не позволяет исследовать процессы и явления на стадии их возникновения, так как они не обладают достаточной чувствительностью.

Частотный спектр процессов Мирового океана очень широк. Для его изучения используются различные установки, созданные на основе использования прямых и параметрических методов измерения. К таким установкам относятся раз- личные уровнемеры, волнографы, притопленные, ныряющие и плавающие буи, донные станции, оснащенные различными датчиками для изучения волновых и неволновых процессов и явлений океана. Многие из этих датчиков созданы на основе использования зависимости вариаций гидросферного давления от изменения состояния гидросферных параметров, уровня ее поверхности. К таким датчикам прежде всего относятся гидрофоны различных конструкций, приемники силового и инерционного типов. Всем вышеуказанным установкам, которые применяются для изучения колебаний и волн Мирового океана и его неволновых процессов, присущи существенные недостатки, которые сводятся к следующему: 1) низкая чувствительность; 2) существенно ограниченный частотный и динамический диапазоны. Для каждой установки присущ хотя бы один из названных недостатков. С созданием лазерных интерферометров [1-5] появилась надежда на создание установок, измеряющих различные гидросферные параметры и которым не присущи вышеуказанные недостатки. Для измерения вариаций гидросферного давления в инфразвуковом и звуковом диапазонах были созданы установки на основе использования современных лазерноинтерференционных методов. Впоследствии они были названы лазерными измерителями вариаций давления гидросферы и лазерными гидрофонами. Данным установкам присущи высокая точность, широкий частотный и динамический диапазоны.

\section{ЛАЗЕРНЫЙ ИЗМЕРИТЕЛЬ ВАРИАЦИЙ ГИДРОСФЕРНОГО ДАВЛЕНИЯ И ЕГО МОДИФИКАЦИИ}

Одними из первых лазерных измерителей вариаций гидросферного давления была установка, принцип действия которой описан в статье [6]. В дальнейшем она несколько раз модифицировалась для устранения недостатков, выявленных в процессе ее испытаний и эксплуатации. Все лазерные измерители гидросферного давления созданы на основе современных лазерноинтерференционных методов. На рис. 1а приведен внешний вид современного лазерного измерителя вариаций гидросферного давления. Прибор представляет собой цилиндрический корпус (1) из нержавеющей стали, который имеет опоры (2) для устойчивости на дне. В съемную крышку прибора (3) вмонтирован кабель ввод (4). Также снаружи прибора расположена эластичная емкость (5) с воздухом. 


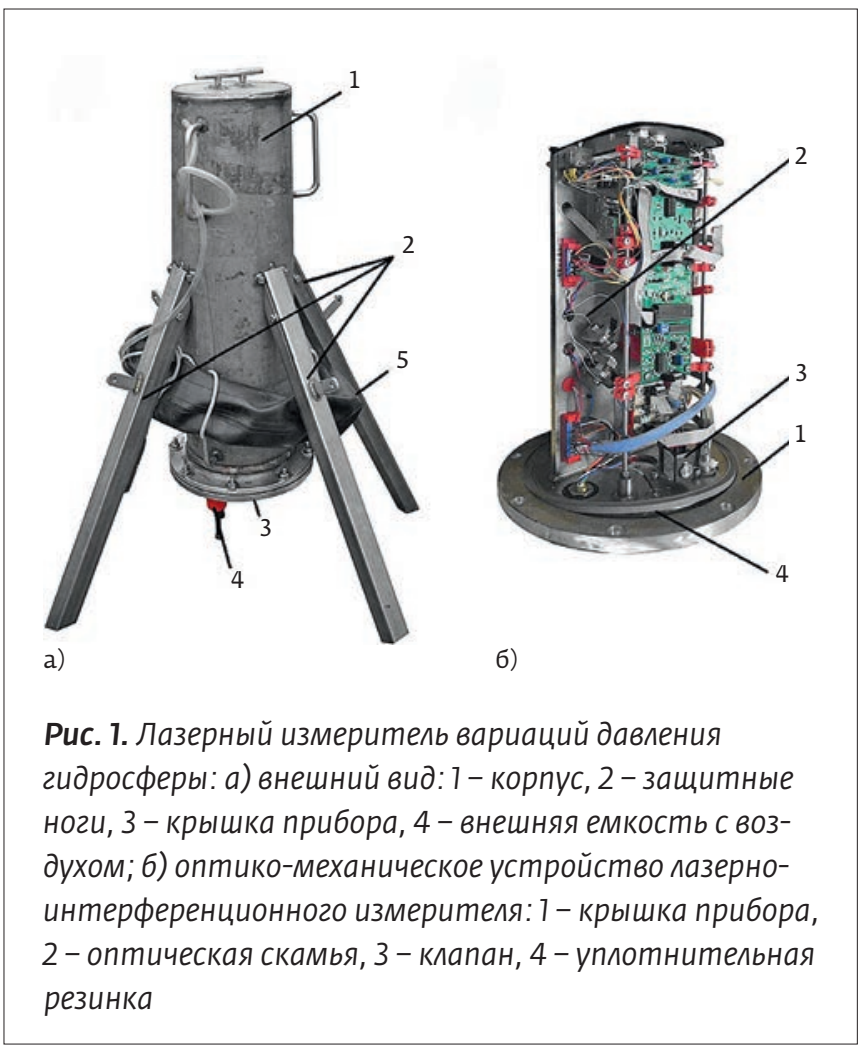

На рис. 1.6 показано оптико-механическое устройство лазерного измерителя вариаций гидросферного давления. Это крышка (1), внутри которой находится компенсационная камера и чувствительный элемент - мембрана с закрепленным в ее центре зеркалом. На крышке жестко крепится оптическая скамья (2 - основная часть интерферометра) и электромагнитный кла- пан (3). Оптическая скамья системы выполнена из нержавеющей стали, что в совокупности с расположенными по обеим сторонам ребрами жесткости и стальными растяжками с верхней стороны позволяет получить большую жесткость конструкции. Герметичность соединения достигается за счет уплотнительного кольца, которое вставляется в паз (4).

Для управления оптико-механическим устройством установка имеет систему регистрации. Это система экстремального регулирования со вспомогательной модуляцией (синхронным детектированием) [7-8]. Она реализована на основе программируемых микроконтроллеров и осуществляет синхронное детектирование, вычисление сигнала компенсации, интегрирование, а также формирование выходного сигнала в цифровой форме.

Чувствительным элементом установки является круглая мембрана. Она закреплена в съемной крышке таким образом, что одна ее сторона контактирует с водой, а другая, с закрепленным на ней зеркалом, обращена внутрь прибора. При этом зеркало является частью измерительного плеча интерферометра. Для удержания мембраны в положении равновесия в момент погружения (или поднятия) прибора на рабочую глубину он имеет систему компенсации внешнего давления (рис. 2). Под действием давления воды в момент погружения воздух из эластичной камеры (1) движется по соединительным трубкам (3, 10) через открытый клапан (9) в камеру. При поднятии происходит то же самое, только в обратном направлении. Таким образом поддерживается постоянное равенство между давлением на внешнюю сторону мембраны (4) и давлением на ее внутреннюю сторону. При достижении прибором необходимой для работы глубины клапан закрывается. Все изменения давления после этого момента уже не будут компенсироваться и могут быть зарегистрированы.

Оптическая схема установки приведена на рис. 3. Она создана на основе модифицированного интерферометра Майкельсона неравноплечего типа с длиной измерительного плеча порядка 30 см. В процессе работы прибора происходит измерение изменения оптической разности хода лучей в опорном 


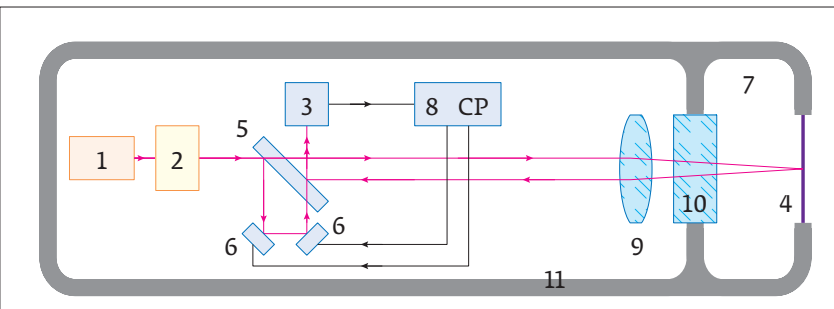

Puc. 3. Оптическая схема пазерного измерителя вариаций давления гидросферы: 1- лазер, 2 - оптический затвор и колииматор, 3 - фотодиод, 4 - мембрана с наклеенным зеркалом, 5 - полупрозрачная пиоскопаралпельная пластина ПИ-100, 6 - плоскопараплельные юстировочные зеркала на пьезокерамических циииндрах muna PZT фирмы Clevite, 7- компенсационная камера, 8 - система регистрации, 9 - линза, 10 - плоскопараплельная пластина, 11 - герметичный корпус прибора

и измерительном плечах интерферометра. Опорное плечо расположено между делительной пластиной (5), зеркалами на пьезокерамических преобразователях (6) и фотодиодом (3). Измерительное плечо расположено между делительной пластиной (5), системой "глаз кошки", состоящей из собирающей линзы (5), мембраны (4) с закрепленным в ее центре зеркалом и фотодиодом (3). На фотодиоде оба луча образуют интерференционную картину, которую настраивают на максимум или минимум яркости. Вариации внешнего давления гидросферы вызывают колебания центра мембраны, что отражается на изменении оптической разности хода лучей интерферометра.

Точность измерений лазерного измерителя вариаций давления гидросферы связана со стабильностью частоты лазерного излучения следующим соотношением:

$$
\Delta l=\mathrm{L} \Delta v / v,
$$

где $L$ - разность оптического хода в плечах интерферометра в начальный момент измерения, $\Delta v / v-$ стабильность частоты излучения, $v$ - частота и $-\Delta v$ ширина полосы лазерного излучения. При этом давление, которое может измерить лазерный измеритель вариаций давления гидросферы, можно рассчитать по формуле для круглой мембраны, закрепленной на краях [9]:

$$
\Delta P=\frac{16 \cdot \Delta l \cdot h^{3} \cdot E}{3 \cdot\left(1-\sigma^{2}\right) \cdot R^{4}},
$$

где: $\Delta l$ - смещение центра мембраны, $h$ - толщина мембраны, E - модуль Юнга, $\sigma$ - коэффициент Пуассона, R - радиус мембраны.

B первой установке в качестве источника излучения использовался частотно-стабилизированный гелий-неоновый лазер ЛГН-303, а в последующих - его аналог, лазер фирмы Melles Griot. Данные лазеры имеют долговременную стабильность частоты излучения $10^{-8}$. При этом в приборе могут использоваться мембраны разной толщины - 0,1; 0,5 и 1 мм (диаметр 10 см). Таким образом, имея мембрану, например, толщиной 0,5 мм (диаметр 10 см) и лазер со стабильностью частоты $10^{-8}$, получаем точность измерений около 1,4 мПа. Данные установки способны регистрировать вариации давления в диапазоне частот от самых низких (близких к нулевым) до 1000 Гц, их динамический диапазон ограничен лишь прочностными характеристиками мембраны, а рабочие глубины теоретически не ограничены.

Мобильный лазерный измеритель вариаций давления гидросферы [10] создан на базе вышеописанного прибора. Несмотря на то, что в обоих измерителях используется один и тот же гелийнеоновый лазер, данный прибор имеет более высокую точность измерений. Конструктивно он во многом повторяет лазерный измеритель вариа-
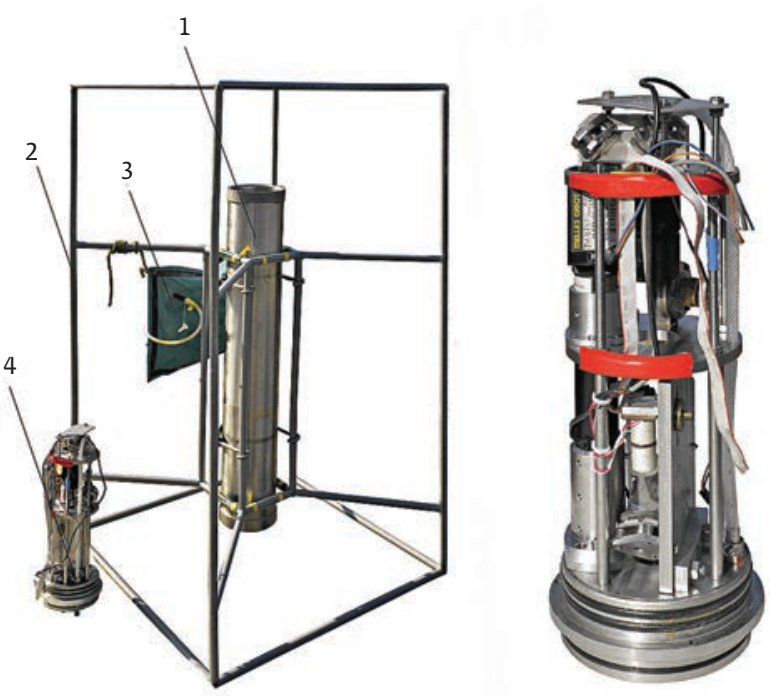

Puc. 4. Внешний вид мобильного лазерного измерителя вариаций давления гидросферы: 1 - корпус, 2 - защитная клетка, 3 - внешняя емкость системы компенсации внешнего давления, 4 - оптико-механическая часть МЛИВДГ, которая в увеличенном варианте показана на рисунке справа 
ций давления гидросферы. Один из вариантов его исполнения представлен на рис. 4. Особенностью его является равноплечий интерферометр Майкельсона, применение которого позволило поднять точность измерений. Ниже рассмотрим это более подробно.

Из анализа выражения (1) вытекает, что минимальная величина, которую может измерить лазерный интерферометр $(\Delta l)$, связана как со стабильностью частоты лазерного излучения $(\Delta v / v)$, так и с оптической разностью хода в плечах интерферометра L. При этом порядок, на который уменьшится величина оптической разности хода в результате уравнивания плеч интерферометра, равен порядку, на который возрастет его точность измерений. То есть, например, имеем интерферометр с оптической разностью хода плеч $\mathrm{L}$, равной 1 м. Если уравнять его плечи с точностью, при которой L будет равна $1 \cdot 10^{-4} \mathrm{M}$, точность измерений возрастет на 4 порядка.

Для интерферометра с длиной измерительного плеча $\mathrm{L}_{\text {и }}$ и $\mathrm{L}_{\mathrm{o}}$ опорного определим $\mathrm{L}$ через соотношение:

$$
L=\left|L_{\text {И }}-L_{O}\right|
$$

Таким образом, исходя из соотношений (1) и (2), можно заключить, что минимальная величина, которую может измерить интерферометр $\Delta l$, или лучшая точность измерений будет наблюдаться при условии:

$$
\mathrm{L}_{\mathrm{U}}=\mathrm{L}_{\mathrm{O}}
$$

В реальных условиях невозможно достигнуть абсолютного равенства (4), поэтому имеет смысл говорить о равенстве с определенной точностью. Таким образом, чем выше точность, с которой уравнены плечи интерферометра Майкельсона, тем выше его точность измерений. В то же время уравнять плечи с точностью, при которой L будет иметь значения от 1 мм и ниже, невозможно без специальных подходов и методов. В связи с этим ниже кратко рассмотрим принцип, на основе которого уравнивались плечи интерферометра в мобильном лазерном измерителе вариаций давления гидросферы, а также лазерных гидрофонах, особенности которых будут рассмотрены позже.

Для этого воспользуемся схемой классического равноплечего интерферометра Майкельсона с дополнительными элементами (рис. 5). Здесь на фазовый модулятор подается тестовый сигнал (синусоидальное напряжение), в результате чего

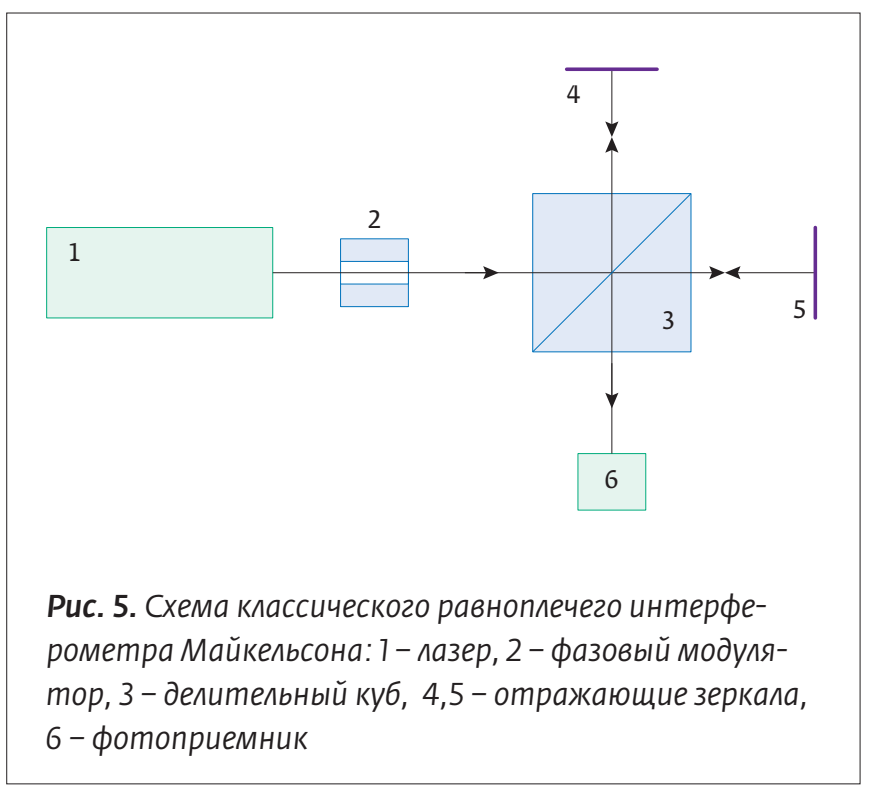

луч лазера модулируется по частоте излучения. При этом фотоприемник регистрирует интенсивность интерференционной картины, которая меняется со временем по закону [11]:

$$
J(t)=J_{1}+J_{2}+2 \sqrt{J_{1} \cdot J_{2}} \cos \left(\frac{4 \pi L(t)}{\lambda(t)}\right),
$$

где $J_{1}$ и $J_{2}$ - интенсивности интерферирующих лучей, $L(t)$ и $\lambda(t)$ - оптическая разность хода плеч интерферометра и длина волны излучения лазера в зависимости от времени. Из этого выражения следует, что колебания $\lambda(t)$ (вызванные фазовым модулятором) будут вызывать колебания интенсивности интерференционной картины. Амплитуда этих колебаний будет зависеть от оптической разности хода плеч интерферометра, то есть будет падать при уменьшении последнего, а при $\lambda(t)=0$ будет стремиться к 0. Таким образом, регулируя с помощью юстированных винтов положение отражающих элементов опорного плеча, мы добиваемся минимальной амплитуды колебаний выходного сигнала. Точность такой настройки ограничена лишь разрешающей способностью юстировки и флуктуациями сигнала, подаваемого на фазовый модулятор. С помощью данного подхода был создан мобильный лазерный измеритель вариаций давления гидросферы, имеющий точность измерений порядка $2,4 \cdot 10^{-5}$ Па, при этом остальные его измерительные характеристики аналогичны характеристикам прототипа.

К сожалению, созданные установки имеют ряд недостатков, которые усложняют их использо- 
вание. Речь идет о габаритных размерах, массе, высоком энергопотреблении и стоимости. Например, первый лазерный измеритель вариаций давления гидросферы имел корпус диаметром 35 см и длиной 100 см, при этом он потреблял мощность около 40 Вт и имел относительно высокую стоимость (на момент создания первого прибора стоимость только лазера составляла 120000 рублей. На данный момент аналогичный лазер стоит 650000 рублей.)

Для создания устройств без вышеперечисленных недостатков был разработан и создан лазерный гидрофон [12]. Он также, как мобильный лазерный измеритель вариаций давления гидросферы, в процессе эксплуатации дорабатывался и модифицировался $[13,14]$. На рис. 6 слева приведен внутренний вид первого лазерного гидрофона, а справа - последней его модификации. Главным отличием данных установок от лазерных измерителей вариаций давления гидросферы является применение полупроводникового лазера вместо гелий-неонового. На момент создания первого лазерного гидрофона, существовало огромное количество полупроводниковых лазеров, имеющих малые размеры и энергопотребление в сравнении с гелий-неоновыми. Например, в первом лазерном гидрофоне использовался полупроводниковый лазерный модуль диметром 16 мм и длиной 30 мM (KLM-650/20), что позволило создать прибор диметром 12 см длинной $30 \mathrm{cM}$, который потреблял мощность 5 Вт (при этом стоимость лазера на момент создания прибора составляла около 700 рублей).

Главной проблемой, которую приходилось решать при создании лазерных гидрофонов, была низкая стабильность частоты излучения полупроводниковых лазеров, что влияло на точность измерений. Для ее решения применялся равноплечий интерферометр Майкельсона. Это позволяло существенно повысить точность измерений лазерных гидрофонов, однако они все равно сильно проигрывали лазерным измерителям вариаций давления гидросферы по этому параметру. К настоящему времени ситуация изменилась, поскольку начали появляться полупроводниковые лазеры, созданные специально для интерферометрии и имеющие высокую стабильность частоты излучения во времени $\left(10^{-6}-10^{-9}\right)$. Например, на рис. 6 справа приведен лазерный гидрофон [13], созданный на лазере типа LCMS-111 со стабильностью частоты излучения $10^{-6}$, что позволило получить точность измерений 2,4 мПа.
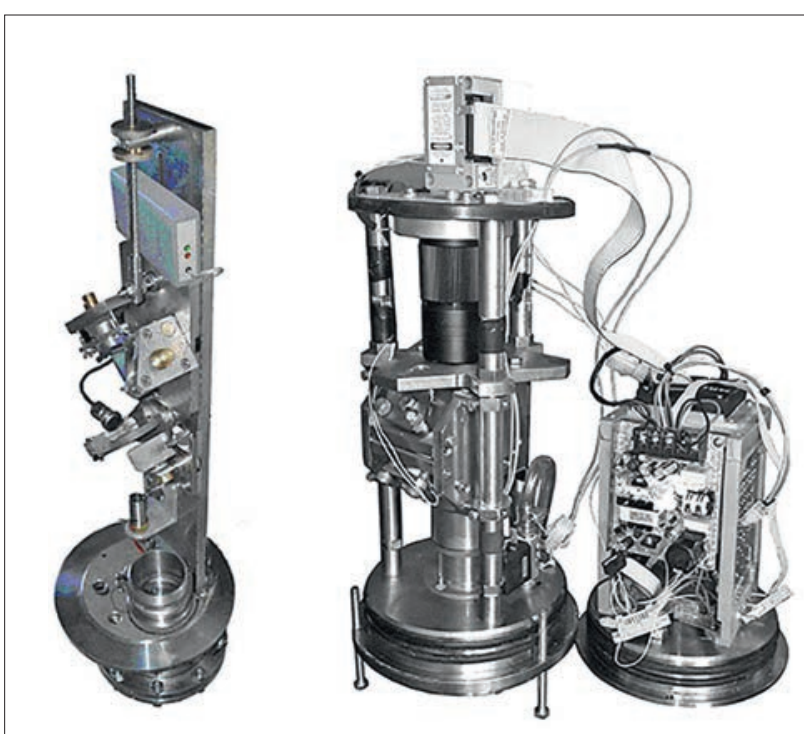

Puс. 6. Внутреннее устройство пазерных гидрофонов

Далее кратко рассмотрим погрешности измерений, характерные для данного типа установок. Речь пойдет о погрешностях, вызванных колебаниями температуры (расширение или сжатие оптических элементов), шумами фотоэлектронной аппаратуры и нестабильностью мощности и частоты лазерного излучения. Их теоретические расчеты приведены в работе [16]. Там было показано, что все они, за исключением ошибки, вызванной тепловым расширением элементов интерферометра, имеют малые значения в сравнении с точностью измерений, и ими можно пренебречь. В то же время эти расчеты показали, что ошибка, вызванная колебаниями температуры, может быть существенной. Экспериментальные исследования также подтвердили этот результат. Для этого прибор помещался в камеру, в которой медленно менялась температура. Во время эксперимента проводилась запись выходного сигнала прибора и температуры внутри него. Точность измерений была ограничена разрядностью цифро-аналогового преобразователя и равнялась величине 0,013 Па (соответственно пороговая чувствительность также ограничена величиной 0,013 Па). В результате было установлено, что данные погрешности могут быть довольно большими. Например, изменение температуры внутри лазерного гидрофона на $7^{\circ} \mathrm{C}$ привело к дрейфу его выходного сигнала на величину, эквивалентную 0,05 Па. Для ее снижения в одной из последних модификаций лазерного гидрофона была реализована оптическая схема с возможностью ее компенсации. В ней коэффи- 
циенты теплового расширения материалов элементов интерферометра и расположение самих элементов были подобраны таким образом, что изменение длины опорного плеча в результате температурных колебаний всегда равнялось изменению длины измерительного плеча [14]. Этот прибор также испытывался в специальной камере, его выходной сигнал при изменении температуры внутри него на $7{ }^{\circ} \mathrm{C}$ не имел ярко выраженного дрейфа, а имел вид прямой линии, что говорит о том, что погрешность, вызванная изменением температуры на $7{ }^{\circ} \mathrm{C}$, не превышала величину 0,013 Па. Другой способ снижения данной погрешности заключается в изготовлении элементов интерферометра из суперинвара совместно с уравниванием плеч интерферометра, а в работе [15] описан вариант, основанный на использовании дополнительного интерферометра для учета влияния температуры.

В заключении технической части данной работы кратко остановимся на особенностях калибровки созданных установок. В связи с тем, что приборы измеряют давление относительно величины их выходного сигнала в начальный момент измерений, результат калибровки задается как определение величины, на которую изменится их выходной сигнал в результате изменения давления на их мембранах на один паскаль. Для этого, калибруемый прибор погружался в бассейн, заполненный водой. Высота начального уровня воды была известна и принята за 0. Велась запись выходного сигнала калибруемого прибора. Далее производилось плавное изменение уровня воды на известную величину, которая затем пересчитывалась в изменение давления по формуле $p=\rho g h$ [17]. На основе данных об изменении уровня воды и напряжения на выходе прибора делался вывод о его чувствительности. Помимо этого калибровка данных установок, проводилась с помощью эталонного гидрофона фирмы "Брюль и Къер" серии 4804. Он разработан специально для калибровки и имеет рабочий диапазон частот от 0,1 Гц до 120 кГц. Этот гидрофон и один из созданных приборов погружались в бассейн, где с помощью специального механизма создавались искусственные низкочастотные колебания с периодом от 1 до 10 с. Данный интервал перекрывается рабочими диапазонами обоих приборов. Далее на основе значений выходных сигналов обоих устройств рассчитывалась чувствительность лазерно-интерференционной установки. Для каждого из созданных приборов калибровка, что первым, что вторым способом, давала схожие результаты.

\section{НЕКОТОРЫЕ НАУЧНЫЕ РЕЗУЛЬТАТЫ, ПОЛУЧЕННЫЕ С ПРИМЕНЕНИЕМ ЛАЗЕРНО-ИНТЕРФЕРЕНЦИОННЫХ ИЗМЕРИТЕЛЕЙ ВАРИАЦИЙ ДАВЛЕНИЯ ГИДРОСФЕРЫ}

С момента создания по настоящее время вышеописанные приборы являются частью лазерноинтерференционного комплекса [18], сформированного на испытательном полигоне м. Шульца б. Витязь залива Петра Великого Японского моря и предназначенного для изучения закономерностей физики генерации, динамики и трансформации волн геосфер звукового и инфразвукового диапазонов. Вне комплекса приборы не раз использовались в экспериментах по изучению собственных колебаний бухт залива Петра Великого Японского моря. Помимо этого лазерный гидрофон и мобильный лазерный измеритель вариаций давления гидросферы несколько раз использовались в экспедиционных работах на испытательном полигоне м. Свободный, о. Сахалин. Таким образом, разработанные установки успешно применяются для мониторинга различных неоднородностей гидросферы. Ниже приведены некоторые научные результаты, полученные с их применением.

Одно из первых исследований, которое проводилось с помощью лазерного гидрофона и лазерного измерителя вариаций давления гидросферы, было посвящено изучению природы взаимодействия низкочастотных гидроакустических волн (32, 245 и 321 Гц) с ветровыми морскими волнами [19]. В ходе этого исследования были проведены три эксперимента. В первом в качестве приемной системы использовался лазерный гидрофон, а в качестве источника излучения - гидроакустический излучатель с частотой излучения 245 Гц. Расстояние между ними было около 1000 м. Излучатель работал в непрерывном режиме. В месте проведения эксперимента высота ветрового волнения колебалась от 0,1 до 0,3 м. Второй эксперимент полностью повторяет первый, только использовался излучатель с частотой излучения 32 Гц. Параметры волнения сходны с первым экспериментом. В третьем эксперименте были задействованы лазерный измеритель вариаций давления гидросферы и гидроакустический излучатель, работающий на частоте 321,6 Гц. Работа проводилась на шельфе Японского моря в течение пяти суток, расстояние между приборами было 5000 м. Высота ветровой волны во время эксперимента колебалась от 0,5 до $2 \mathrm{M}$. 
Поскольку лазерно-интерференционные измерители обладают широким рабочим диапазоном частот, то в сигналах, принятых в момент излучения, содержатся как гармоники искусственного гидроакустического сигнала, так и гармоники, обусловленные ветровым волнением. Предполагалось, что ветровое волнение модулирует излученные гидроакустические волны, но после обработки данных всех экспериментов установлено, что морские ветровые волны с амплитудами от 0,2 до 2 м не оказывают модулирующее воздействие на низкочастотные гидроакустические волны с частотами 33, 245, 321 Гц.

Часть работ, проводимых с помощью лазерноинтерференционных измерительных приборов, были посвящены изучению различных аспектов природы ветровых волн. Например, работа [20] описывает серию экспериментов, проводимых для исследования динамики ветровых волн в бухте Витязь залива Петра Великого Японского моря. Там использовались две пространственноразнесенные лазерно-интерференционные установки. В ходе эксперимента было установлено, что в бухте Витязь существуют два вида ветровых волн: волны, пришедшие извне, и волны, которые генерируются ветром в самой бухте. В целях изучения их динамики были обработаны массивы данных, полученные в августе 2011 года и в январе 2012 года. На основе результатов обработки этих данных оценивался вклад ветра в поверхностное волнение, характерное для бухты Витязь. На основе данных, полученных в январе 2012 года, а также записей камер видеомониторинга выявлена четкая корреляция между присутствием и отсутствием ветрового волнения, зарождающегося в бухте, и ветром. Также выявлена связь между наличием этого волнения и ледяного покрова, который периодически пригонялся в бухту ветром и выгонялся из нее. Помимо этого было установлено, что, по мере распространения по шельфу убывающей глубины, ветровая волна при взаимодействии с дном теряет часть своей энергии (передает дну), что приводит к трансформации ее спектра, а энергия в нем перераспределяется в более высокочастотную область (рис. 7). Величины изменений зависят не только от длины ветровых волн и степени уменьшения глубины, но и от их амплитуд.

В работе [21] на основе результатов анализа данных, полученных с лазерного гидрофона за 2010, 2012 и 2013 годы, была выведена общая функция изменения периода поверхностных гравитаци- онных и ветровых морских волн на временных интервалах произвольной длины. Обсуждаются вопросы практического применения данной функции для расчетов основных характеристик волнения. В качестве исходных данных использовались спектрограмма участка записи лазерного гидрофона и гидродинамическая модель распространения поверхностных волн в водоеме конечной глубины. Представлен метод расчета пространственно-временного распределения амплитуды давления, мгновенных значений горизонтальной и вертикальной скоростей, горизонтальных и вертикальных смещений частиц среды, вызванных поверхностным морским волнением, на произвольной глубине в приближении мелкого моря.

Некоторые особенности возникновения морских инфрагравитационных волн исследовались в работе [22]. В ней при спектральной обработке данных лазерного измерителя вариаций гидросферного давления в диапазоне периодов от 30 с до 5 мин были обнаружены группы колебаний с устойчивыми максимумами на периодах порядка 46 с, 1 мин 20 с и 2 мин 40 с (рис. 8), которые относятся к спектру инфрагравитационных морских волн.

Установлено, что выделенные группы инфрагравитационных морских волн существуют

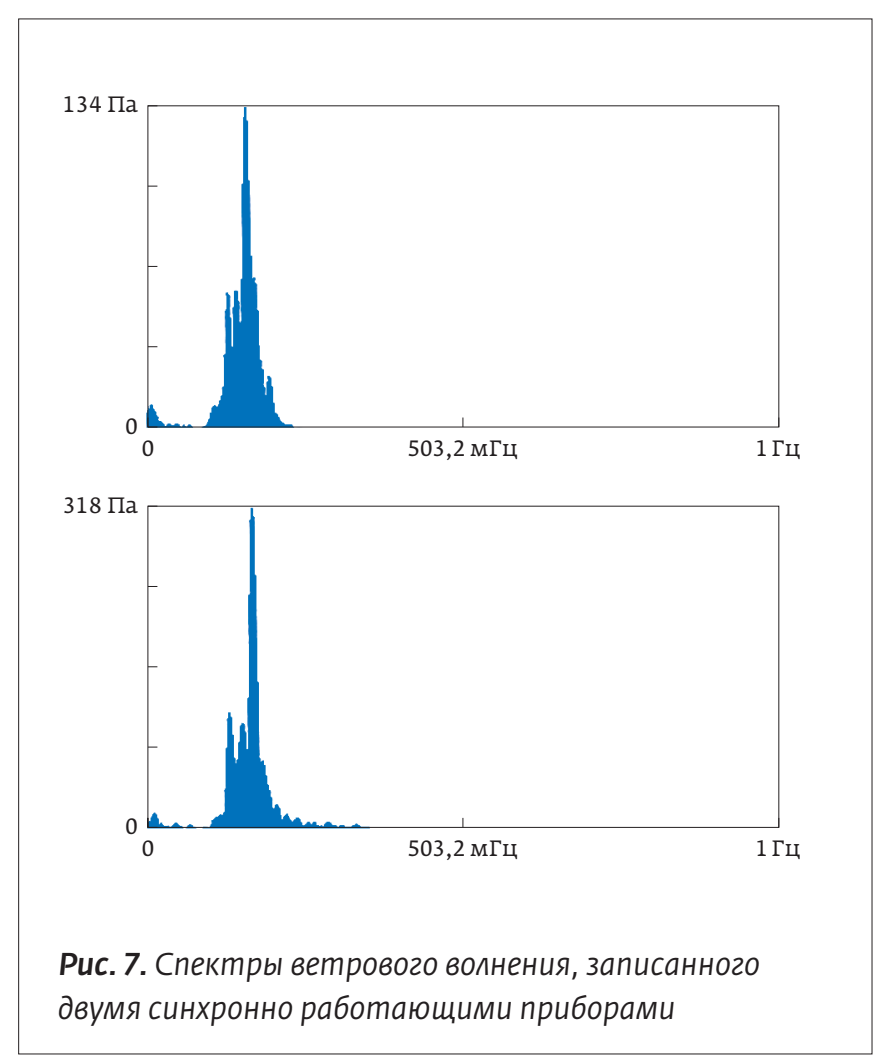




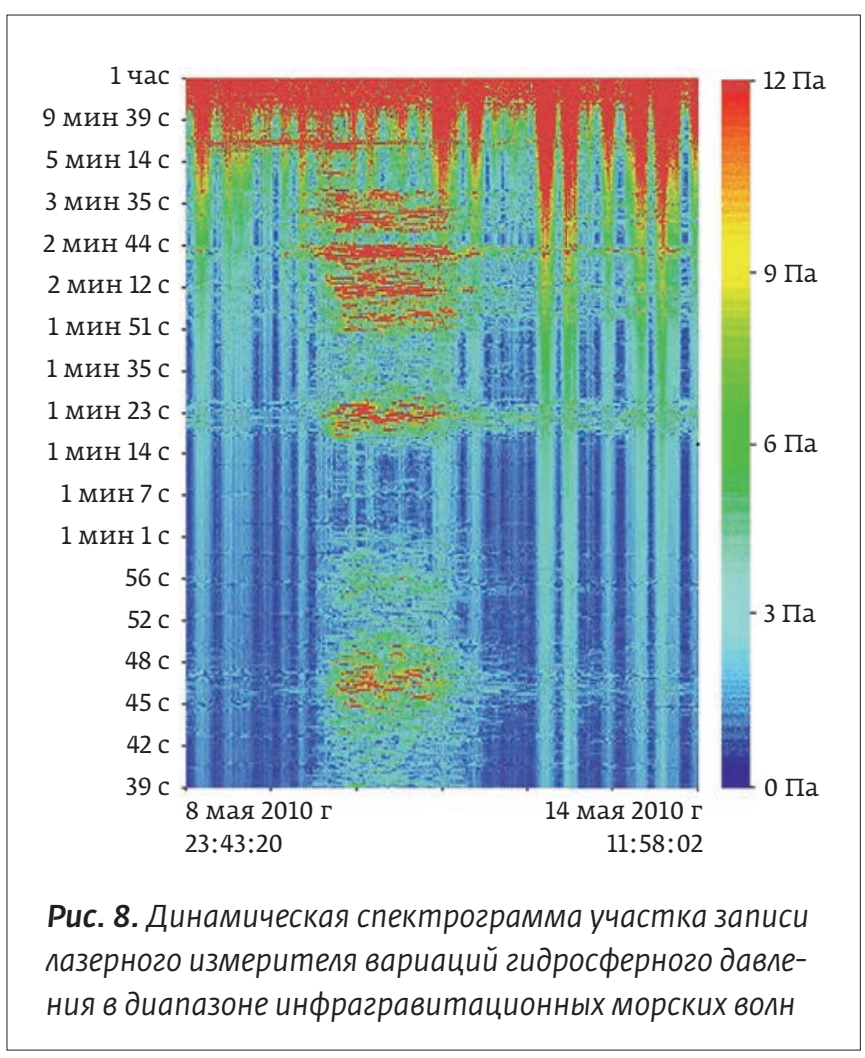

практически всегда при любом ветровом волнении, т.е. при местном ветровом волнении, возникшем в бухте, и при ветровом волнении, пришедшем с открытой части Японского моря. Амплитуды этих колебаний все время меняются и имеют максимумы на участках, на которых происходит усиление амплитуд колебаний с периодами от 5 до 14 с. Т.е. приход в бухту Витязь зыби, которая возбуждается в открытой части Японского моря, усиливает колебания с периодами 2 мин 40 с, 1 мин 20 с и 46 с. Во временном интервале, в котором амплитуда колебаний, лежащих в диапазоне ветровых волн и зыби, возрастает, возрастает также и амплитуда колебаний, лежащих в диапазоне от 30 с до 5 мин (то есть 2 мин 40 с, 1 мин 20 с, 46 с). Интересным является тот факт, что наиболее сильно амплитуду исследуемых колебаний усиливают волны, у которых сильно изменяется период со временем. Выделенные колебания (рис. 8), в отличие от поверхностных ветровых волн, не испытывают вариаций, вызванных приливными составляющими. Давление, вызванное выделенными колебаниями и регистрируемое лазерным измерителем вариаций гидросферного давления, не зависит от величины водного столба в месте расположения регистратора. Т.е. можно утверж- дать, что выделенные колебания относятся к стоячим волнам, для которых в фиксированный момент времени создаваемое ими давление на любой глубине от поверхности моря до дна будет одинаковым.

В работе [23] объектом исследования являются сверхнизкочастотные колебания, регистрируемые в бухте Витязь залива Петра Великого Японского моря, период которых лежит в интервале от 16 до 18 мин. Данные возмущения идентифицированы как собственные колебания бухты, что было подтверждено при проведении модельных расчетов, выполненных с применением дифференциально-разностной модели, базирующейся на теории мелкой воды. Полученные в расчетах результаты хорошо совпадают с полученными экспериментальными данными по колебаниям с периодами 17 мин 23 с. Применение описанных лазерно-интерференционных систем позволило установить, что колебания с периодами 16-18 мин регистрируются только в бухте Витязь, а вне бухты, с другой стороны м. Шульца залива Петра Великого, их нет.

Также при обработке данных, полученных с помощью лазерно-интерференционных измерителей, установлено, что проходящие через бухту или вблизи бухты циклоны возбуждают в ней колебания, соответствующие периоду 17 мин 28 с. Но с течением времени после действия циклонов период этих колебаний возрастает, а амплитуда падает.

С целью изучения закономерностей генерации морских внутренних волн атмосферными процессами [24] были обработаны синхронные ряды данных береговых лазерных деформографов, лазерного нанобарографа и лазерного измерителя вариаций давления гидросферы, установленного на шельфе на глубине 27 м южнее м. Шульца. Лазерный нанобарограф был установлен в лабораторном помещении на удалении около 50 м от 52,5 метрового лазерного деформографа и на расстоянии 370 м от лазерного измерителя вариаций давления гидросферы. Измерения велись непрерывно в течение четырех месяцев (начиная с 31 мая), а затем были прерваны из-за поломки лазерного измерителя вариаций давления гидросферы. Основное внимание при анализе полученных экспериментальных данных было уделено частотному диапазону так называемых короткопериодных внутренних волн, соответствующих периодам от 5 до 20 мин. 
В результате анализа многочисленных экспериментальных данных рассматриваемого диапазона было установлено следующее: появление колебаний гидросферного давления в рассматриваемом диапазоне периодов, зарегистрирован ${ }^{-}$ ных лазерным измерителем вариаций давления гидросферы, практически всегда сопровождалось колебаниями атмосферного давления; резкие изменения атмосферного давления сопровождались колебаниями давления гидросферы (при этом в записях лазерного измерителя вариаций давления гидросферы никогда не наблюдалось возбуждение колебаний диапазона короткопериодных внутренних волн); синхронно с вариациями атмосферного давления наблюдались вариации деформаций верхнего слоя земной коры; в редких случаях вариации гидросферного давления и деформации верхнего слоя земной коры рассматриваемого частотного диапазона не сопровождались соответствующими колебаниями атмосферного давления.

\section{ЗАКЛЮЧЕНИЕ}

На основе современных лазерно-интерференционных методов созданы следующие измеритель- ные системы: лазерный измеритель вариаций давления гидросферы, мобильный лазерный измеритель вариаций давления гидросферы и лазерный гидрофон. Они предназначены для измерения колебаний гидросферного давления. Их частотный диапазон снизу ограничен лишь временем измерения (условно от 0 Гц), а сверху возможностями цифровой системы регистрации (1000 Гц). Точность их измерений может достигать 1 мПа. Динамический диапазон ограничен лишь прочностными характеристиками мембраны. Глубина погружения теоретически может быть любой.

В процессе обработки данных, полученных с их применением, выявлены новые закономерности в природе ветровых волн и собственных колебаний бухты Витязь. Также исследовались особенности возникновения инфрагравитационных волн, взаимодействие низкочастотных гидроакустических и ветровых волн, связь между колебаниями атмосферы и литосферы и т.д.

Работа выполнена при частичной финансовой поддержке гранта РФФИ (18-05-80011, опасные явления) и программы Президиума ДВО РАН.

\section{ЭССЕНТОПТИКС (|[) ESSENTOPTICS}

\section{LINZA 150}

Первый в мире спектрофотометр для измерения пропускания и отражения линз и объективов

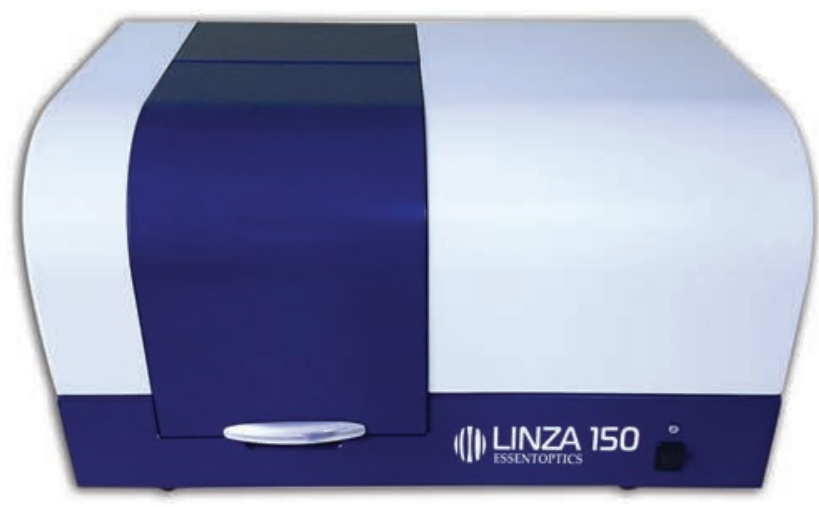

\section{Спектрофоотометр LINZA 150}

Новая функция: измерение пропускания и отражения от асферических поверхностей

LINZA 150 Spectrophotometer

New feature: transmittance and reflectance measurement of aspheric lens 


\section{СПИСОК ЛИТЕРАТУРЫ}

1. Долгих Г.И., Долгих С. Г., Ковалев С. Н., Корень И. А., Новикова О. В., Овчаренко В. В., Окунцева О.П., Швец В.А., Чупин В.А., Яковенко С. В. Лазерный нанобарограф и его применение при изучении баро-деформационного взаимодействия. Физика Земли. 2004; № 8: 82-90.

2. Долгих Г.И., Купцов А. В., Ларионов И.А., Марапулец Ю. В., Швец В.А., Шевцов Б. М., Широков О. П., Чупин В.А., Яковенко С. В. Деформационные и акустические предвестники землетрясений. Докиады академии наук. 2007; 413(1): 96-100.

3. Долгих Г.И., Ковалев С. Н., Корень И.А., Овчаренко В. В. Двухкоординатный лазерный деформограф. Физика Земпи. 1998; 11: 76-81.

4. Долгих Г. И. Некоторые результаты экспериментального исследования характеристик сейсмоакустических сигналов, возбуждаемых низкочастотным гидроакустическим излучателем. Акустический журнап. 1998; 44(3): 358361.

5. Долгих Г.И., Валентин Д. И., Долгих С. Г., Ковалев С. Н., Корень И.А., Овчаренко В. В., Фищенко В. К. Применение лазерных деформографов вертикальной и горизонтальной ориентации в геофизических исследованиях переходных зон. Физика Земли. 2002; 8: 69-73.

6. Долгих Г.И., Долгих С. Г., Ковалев С. Н., Швец В. А., Чупин В. А., Яковенко С. В. Лазерный измеритель вариаций давления гидросферы. Приборы и техника эксперимента. 2005; 6: 137-138.

7. Долгих Г.И., Ковалев С. Н., Швец В.А., Яковенко С. В. Цифровая система регистрации лазерно-интерференционных установок. Приборы и техника эксперимента. 2008; 5: 158-159.

8. Швец В.А. Контроллер-детектор регистрирующей системы лазерного. Приборы и техника эксперимента. 2011; (1): 159-160.

9. Ландау Л.Д., Лифшиц Е. М. Теоретическая физика. Т. VII. Теория упругости М.: Наука. 1987.

10. Долгих Г.И., Плотников А.А., Будрин С. С. Мобильный лазерный измеритель вариаций давления гидросферы. Приборы и техника эксперимента. 2011; 4: 161-162

11. Матвеев А. Н. Oптика. М.: Высшая школа. 1985.

12. Долгих Г.И., Плотников А.А., Швец В.А. Лазерный гидрофон. Приборы и техника эксперимента. 2007; (1): 159-160.

13. Долгих Г.И., Долгих С. Г., Плотников А. А., Чупин В. А., Яковенко С. В. Лазерный гидрофон на основе зеленого лазера LCM-S-11. Приборы и техника эксперимента. 2013; (5):140-141.

14. Долгих С.Г., Будрин С. С., Плотников А.А. Лазерный измеритель вариаций давления гидросферы с механической системой компенсации температурного воздействия - Океанопогия, 2017, Т. 57, № 4, с. 663-666.

15. Долгих Г.И., Плотников А.А., Будрин С. С. Лазерно-интерференционный измеритель давления гидросферы с учетом изменений температуры. Приборы и техника эксперимента. 2015; (5): 149-150.

16. Dolgikh G., Dolgikh S., Kovalyov S., Chupin V., Shvets V., Yakovenko S. Super-low-frequency laser instrument for measuring hydrosphere pressure variations. Journal of Marine Science and Technology. 2009; 14(4): 436-442.

17. Громов С. В. и др. Физика. 7. - М.: Просвещение. 2002.

18. Долгих Г.И., Долгих С. Г., Валентин Д. И., Ковалев С. Н., Корень И.А., Овчаренко В. В., Яковенко С. В. Сейсмоакустико-гидрофизический комплекс для мониторинга системы "атмосфера-гидросфера-литосфера". Приборы и техника эксперимента. 2002; (3): 120-122.

19. Долгих Г.И., Долгих С. Г., Плотников А. А., Чупин В.А., Яковенко С. В. Взаимодействие низкочастотных гидроакустических волн с ветровыми морскими волнами. Докиады академии наук. 2010; 430(2): 257-260.

20. Долгих Г.И., Будрин С. С., Долгих С. Г., Овчаренко В. В., Плотников А.А., Чупин В.А., Швец В.А, Яковенко С. В. Динамика ветровых волн при движении по шельфу убывающей глубины. Докиады академии наук. 2012; 447(4): 445449.

21. Долгих Г.И., Будрин С. С. Некоторые закономерности в динамике периодов ветровых волн. Доклады академии наук. 2016; 468(3): 332.

22. Долгих Г.И., Плотников А.А. Особенности возникновения морских инфрагравитационных волн. Метеорология и гидрология. 2018; 8: 33-38.

23. Долгих Г.И., Долгих С. Г., Смирнов С. В., Чупин В. А., Швец В. А., Яковенко С. В. Инфразвуковые колебания японского моря. Докиады академии наук. 2011; 441(1): 98-102.

24. Долгих Г.И., Будрин С. С., Долгих С. Г., Овчаренко В. В. Чупин В.А., Швец В.А. Яковенко С. В. Морские внутренние волны и атмосферные депрессии. Докиады академии наук. 2015; 462(5):601-604.

\section{REFERENCE}

1. Dolgikh G. I., Dolgikh S. G., Kovalev S. N., Koren' I.A., Novikova O.V., Ovcharenko V.V., Okuntseva O. P., SHvets V.A., CHupin V.A., YAkovenko S. V. Lazernyj nanobarograf i ego primenenie pri izuchenii barodeformatsionnogo vzaimodejstviya. Fizika Zemli. 2004; № 8: 82-90.

2. Dolgikh G. I., Kuptsov A.V., Larionov I.A., Marapulets YU.V., SHvets V.A., SHevtsov B.M., SHirokov O.P., CHupin V.A., YAkovenko S.V. Deformatsionnye i akusticheskie predvestniki zemletryasenij. Doklady akademii nauk. 2007; 413(1): 96-100.

3. Dolgikh G. I., Kovalev S. N., Koren' I.A., Ovcharenko V. V. Dvukhkoordinatnyj lazernyj deformograf. Fizika Zemli. 1998; 11: 76-81.

4. Dolgikh G. I. Nekotorye rezul'taty ehksperimental'nogo issledovaniya kharakteristik sejsmoakusticheskikh signalov, vozbuzhdaemykh nizkochastotnym gidroakusticheskim izluchatelem. Akusticheskij zhurnal. 1998; 44(3): 358-361.

5. Dolgikh G. I., Valentin D. I., Dolgikh S. G., Kovalev S. N., Koren' I.A., Ovcharenko V. V., Fishhenko V. K. Primenenie lazernykh deformografov vertikal'noj i gorizontal'noj orientatsii v geofizicheskikh issledovaniyakh perekhodnykh zon. Fizika Zemli. 2002; 8: 69-73.

6. Dolgikh C. I., Dolgikh S. G., Kovalev S. N., SHvets V.A., CHupin V.A., YAkovenko S. V. Lazernyj izmeritel' variatsij davleniya gidrosfery. Pribory i tekhnika ehksperimenta. 2005; 6: 137-138.

7. Dolgikh G. I., Kovalev S. N., SHvets V.A., YAkovenko S.V. TSifrovaya sistema registratsii lazerno-interferentsionnykh ustanovok. Pribory i tekhnika ehksperimenta. 2008; 5: 158-159.

8. SHvets V.A. Kontroller-detektor registriruyushhej sistemy lazernogo. Pribory i tekhnika ehksperimenta. 2011; (1): 159-160.

9. Landau L. D., Lifshits E. M. Teoreticheskaya fizika. T. VII. Teoriya uprugosti. M. Nauka. 1987.

10. Dolgikh G. I., Plotnikov A.A., Budrin S. S. Mobil'nyj lazernyj izmeritel' variatsij davleniya gidrosfery. Pribory i tekhnika ehksperimenta. 2011; 4: 161-162.

11. Matveev A. N. Optika. M.: Vysshaya shkola. 1985.

12. Dolgikh G. I., Plotnikov A.A., SHvets V.A. Lazernyj gidrofon. Pribory i tekhnika ehksperimenta. 2007; (1): 159-160.

13. Dolgikh G. I., Dolgikh S. G., Plotnikov A.A., CHupin V. A., YAkovenko S. V. Lazernyj gidrofon na osnove zelenogo lazera LCM-S-11. Pribory i tekhnika ehksperimenta. 2013; (5):140-141.

14. Dolgikh S. G., Budrin S. S., Plotnikov A.A. Lazernyj izmeritel' variatsij davleniya gidrosfery s mekhanicheskoj sistemoj kompensatsii temperaturnogo vozdejstviya - Okeanologiva, 2017, T. 57, № 4, c. 663-666.

15. Dolgikh G. I., Plotnikov A. A., Budrin S. S. Lazerno-interferentsionnyj izmeritel' davleniya gidrosfery s uchetom izmenenij temperatury. Pribory i tekhnika ehksperimenta. 2015; (5): 149-150.

16. Dolgikh G., Dolgikh S., Kovalyov S., Chupin V., Shvets V., Yakovenko S. Super-low-frequency laser instrument for measuring hydrosphere pressure variations. Journal of Marine Science and Technology. 2009; 14(4): 436-442.

17. Gromov S. V. Fizika - 7: uchebnik / S. V. Gromov, N. A. Rodina - M.: Prosveshhenie. 2002

18. Dolgikh G. I., Dolgikh S. G., Valentin D. I., Kovalev S. N., Koren' I. A., Ovcharenko V.V., YAkovenko S. V. Sejsmoakustiko-gidrofizicheskij kompleks dlya monitoringa sistemy "atmosfera-gidrosfera-litosfera". Pribory i tekhnika ehksperimenta. 2002; (3): 120-122.

19. Dolgikh G. I., Dolgikh S. G., Plotnikov A.A., CHupin V.A., YAkovenko S. V. Vzaimodejstvie nizkochastotnykh gidroakusticheskikh voln s vetrovymi morskimi volnami. Doklady akademii nauk. 2010; 430(2): 257-260.

20. Dolgikh G. I., Budrin S. S., Dolgikh S. G., Ovcharenko V.V., Plotnikov A.A., CHupin V.A., SHvets V.A, YAkovenko S. V. Dinamika vetrovykh voln pri dvizhenii po shel'fu ubyvayushhej glubiny. Doklady akademii nauk. 2012; 447(4): 445-449.

21. Dolgikh G. I., Budrin S. S. Nekotorye zakonomernosti v dinamike periodov vetrovykh voln. Doklady akademii nauk. 2016; 468(3): 332.

22. Dolgikh G. I., Plotnikov A.A. Osobennosti vozniknoveniya morskikh infragravitatsionnykh voln. Meteorologiya i gidrologiva. 2018; 8: 33-38.

23. Dolgikh G. I., Dolgikh S. G., Smirnov S. V., CHupin V.A., SHvets V.A., YAkovenko S. V. Infrazvukovye kolebaniya yaponskogo morya. Doklady akademii nauk. 2011; 441(1): 98-102.

24. Dolgikh G. I., Budrin S. S., Dolgikh S. G., Ovcharenko V. V. CHupin V.A., SHvets V.A. YAkovenko S. V. Morskie vnutrennie volny i atmosfernye depressii. Doklady akademii nauk. 2015; 462(5):601-604. 


\section{N TEХHИЧЕСКАЯ ЯPMAPKA}
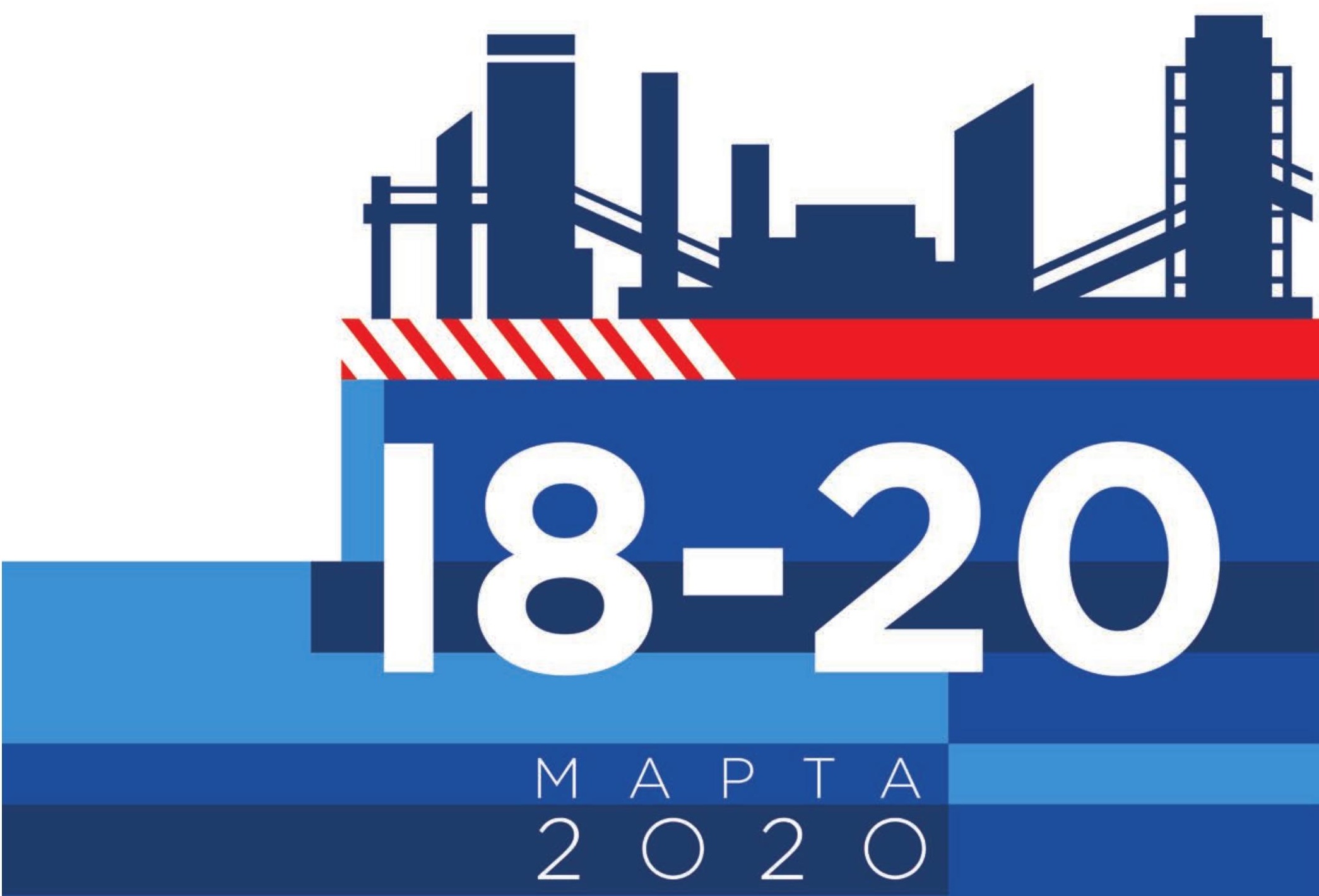

КВЦ «ЭКСПОФОРУМ»

Петербургское шоссе, 64

ВЕДУЩЕЕ ПРОМЫШЛЕННОЕ МЕРОПРИЯТИЕ СЕВЕРО-ЗАПАДА

+78123209032 | bolgova@restec.ru | ptfair.ru 